\title{
Relationship of visual impairment and peripheral artery disease with the occurrence of diabetic foot ulcers in Dr. Moewardi Hospital
}

Original article

Okti Sri Purwantia,* Krisna Yetti ${ }^{b}$, Tuti Herawatib

aSchool of Nursing, Faculty of Health Science, Universitas Muhammadiyah Surakarta, Kartasura 57162, Indonesia

${ }^{b}$ Faculty of Nursing, Universitas Indonesia, Depok 16424, Indonesia

Received: 21 October 2018; Accepted: 28 December 2018; Published: 20 June 2019

Abstract: Objective: One of the diabetes mellitus (DM) complications is foot ulcers. Foot ulcers are influenced by many factors. DM puts patients at risk of injury because of visual impairment. Hyperglycemia can damage blood vessels, which results in peripheral artery disease (PAD). The purpose of this study was to find the relationship of visual impairment and PAD with diabetic foot ulcers.

Methods: This research used observational analytic study with case-control methods. It used purposive sampling in 34 DM patients with foot ulcers and $34 \mathrm{DM}$ patients without foot ulcers. The research instruments were an interview guide to assess visual impairment, physical examination to assess PAD, and documentation study, which was used to know the incidence of diabetic ulcers.

Results: The results showed that the respondents who experienced ulcers with visual impairment were $44.1 \%$ and the respondents who had foot ulcers with PAD were 73.5\%. The results of statistical tests showed that there was no relationship between visual impairment and the incidence of ulcers $(P=0.166)$. The respondents with PAD will have a chance to suffer from foot ulcers 5.808 times higher than those who do not have PAD.

Conclusions: There is no relationship between visual impairment and the incidence of diabetic foot ulcers in Dr. Moewardi Hospital, but there is relationship between PAD and the incidence of diabetic foot ulcers in Dr. Moewardi Hospital. Suggestions of this study are to do foot screening and educate about the importance of foot care to prevent the occurrence of diabetic ulcers.

Keywords: visual impairment • peripheral artery disease $\bullet$ foot ulcers $\bullet$ diabetes mellitus $\bullet$ artery disease $\bullet$ retinopathy

(c) Shanxi Medical Periodical Press.

\section{Introduction}

Diabetes mellitus (DM) is a chronic disease that occurs when the pancreas does not produce enough insulin or the body is unable to utilize insulin, resulting in hyperglycemia. ${ }^{1}$ Prevalence of diabetes Indonesia (20-79 years) shows 12 million at 2010. Estimates of diabetes in Indonesia increasing become 12 million in $2030 .^{2}$ Diabetes can lead to complications of stroke, coronary heart disease, arterial disease, foot ulcer, visual impairment, and amputation..$^{3-6}$

One of the complications that affect the quality of life is foot disorder. The prevalence of foot ulcers in diabetic patients is approximately $15 \% .^{7}$ Though foot ulcers have low prevalence but can lead to hospitalization, increased costs for diabetics, and amputation. ${ }^{8}$ Control of prolonged high blood glucose level will result in damage to blood vessel walls. This leads to

How to cite this article: Purwanti OS, Yetti K, Herawati T. Relationship of visual impairment and peripheral artery disease with the occurrence of diabetic foot ulcers in Dr Moewardi Hospital. Front Nurs. 2019; 2: xx-xx.

Ә Open Access. ๑ 2019 Okti Sri Purwanti et al., published by Sciendo. (cc)BY-NC-ND This work is licensed under the Creative Commons Attribution NonCommercial-NoDerivatives 4.0 License. 
inflammation in the vascular endothelium, which results in increased progression of atheroma plaque formation, resulting in progressive narrowing of the vascular lumen. An increased risk of peripheral artery disease (PAD) is determined by the duration of DM. Prevalence of PAD is four times more common in diabetic patients. The absence of pulse in the periphery may predict poor prognosis of the foot to be amputated with or without foot ulcers. The presence of a history of leg pain and no pulse on both legs increases the likelihood of vascular insufficiency. 9,10

In addition to PAD, other factors affecting foot ulcers are vision impairment. Impaired vision in diabetic patients or the elderly will affect balance, mobilization, and walking. ${ }^{9}$ Impaired vision of diabetes occur due to hyperglycemia, which causes thickening of the basement membrane, decreasing peripheral permeability and luminal narrowing in the retina or lenses that may result in diabetic retinopathy. ${ }^{11}$ The purpose of this study was to determine the relationship of visual impairment and PAD with the occurrence of foot ulcers in patients with DM.

\section{Materials and methods}

This research was a quantitative study. This type of research was an observational analytic study with casecontrol methods. The sample was foot ulcer patients and diabetic patients. The sampling technique used in this study was purposive sampling. Inclusion criteria were diabetic patients who had foot ulcers from May 2012 to December 2012 and the patients who were willing to participate in this study. There were 34 patients with foot ulcers and 34 diabetics without foot ulcers. The research was done in outpatient and inpatient care units ( 1 and 3 bedrooms) of Dr. Moewardi Surakarta Hospital. The study time was September 2012 to January 2013. Visual impairment was assessed by using an interview guide, PAD by performing examination of pulse on both legs and diabetic foot ulcers based on medical record documentation. Chi-square test was used for data analysis.

\section{Results}

Table 1 shows that of respondents who experienced ulcers, as many as $44.1 \%$ experienced visual impairment. Of all respondents who did not have ulcers, $58.8 \%$ had vision problems. The results of statistical tests showed no association between visual impairment and the incidence of ulcers $(P=0.166)$.

Table 2 shows that of respondents with foot ulcers, $73.5 \%$ experienced PAD. Of all respondents who did not have ulcers, only $32.4 \%$ experienced PAD. The result of statistical test shows that there was a significant correlation between PAD and the incidence of diabetic foot ulcers $(P=0.001)$. PAD is a risk factor for occurrence of foot ulcers because odds ratio $(\mathrm{OR})=5.808(95 \% \mathrm{Cl} 2.038-16.552)$. This indicates that PAD respondents have 5.808 chance of ulcers compared to respondents who do not have PAD.

\section{Discussion}

Based on the results, it can be seen that as high as $44.1 \%$ of respondents with ulcers experienced visual

\begin{tabular}{|c|c|c|c|c|c|c|c|c|}
\hline \multirow[t]{2}{*}{ Items } & \multicolumn{2}{|c|}{ No foot ulcer } & \multicolumn{2}{|c|}{ Foot ulcer } & \multirow[t]{2}{*}{$P$} & \multirow[t]{2}{*}{ Odds ratio (OR) } & \multicolumn{2}{|c|}{ 95\% confidence interval $(\mathrm{Cl})$} \\
\hline & $n$ & $\%$ & $n$ & $\%$ & & & Minimum & Maximum \\
\hline No visual impairment & 14 & 41.2 & 19 & 55.9 & 0.166 & 0.553 & 0.211 & 1.146 \\
\hline Vision impairment & 20 & 58.8 & 15 & 44.1 & & & & \\
\hline Total & 34 & 100 & 34 & 100 & & & & \\
\hline
\end{tabular}

Table 1. Relationship between visual impairment and the incidence of diabetic foot ulcers in the general hospital of Dr. Moewardi Surakarta in December 2012

\begin{tabular}{lccccccc}
\hline \multirow{2}{*}{ Items } & \multicolumn{2}{c}{ No foot ulcer } & \multicolumn{2}{c}{ Foot ulcer } & $P$ & Odds ratio (OR) & \multicolumn{2}{c}{ 95\% confidence interval (Cl) } \\
\cline { 2 - 5 } & $n$ & $\%$ & $n$ & $\%$ & & 0.001 & Minimum \\
\hline \hline No PAD & 23 & 67.6 & 9 & 26.5 & & 2.808 & Maximum \\
PAD & 11 & 32.4 & 25 & 73.5 & & 16.552 \\
Total & 34 & 100 & 34 & 100 & & \\
\hline
\end{tabular}

Table 2. Relationship between peripheral artery disease (PAD) and the incidence of diabetic foot ulcers in the general hospital of Dr. Moewardi Surakarta on December 2012. 
impairment and $55.8 \%$ respondents who did not have ulcers experienced visual impairment. This is in contrast to the study of Melville et al., ${ }^{3}$ where after 20 years of DM diagnosis, almost all respondents of type $1 \mathrm{DM}$ have retinopathy, whereas $60 \%$ of retinopathy occurs in type 2 DM respondents.

Visual disturbance variables correlated significantly with foot ulcer occurrence $(O R=0.160)$. Respondents having visual impairment have a possibility 0.160 times for foot ulcers compared to respondents with no visual disturbance. This is consistent with the research of Prompers et al. ${ }^{12}$ that the severity of vision impairment (the inability of a person to read the newspaper after being corrected) who have PAD or do not have PAD is associated with 1 year of ulcers $(P=0.007)$.

Visual impairment occurs due to the accumulation of sorbitol in the eyepiece, whose function is to withdraw water, which further damages the clarity of the eye. ${ }^{11}$ Other eye problems such as cataracts, glaucoma, and double vision affect routine self-care behaviors such as foot inspection and daily care, which can lead to foot ulcers or amputation. ${ }^{13}$ All of the respondents with or without ulcers experience the same process, i.e., vision disorders, e.g., retinopathy, cataract, or presbyopia due to which they have not or have been wearing glasses. Most of respondents were diagnosed with DM in older age, when it was easy to experience vision problems such as presbyopia and cataracts. Although respondents experience visual impairment, providing family support to help check legs, prevent injuries, create a safe environment, and use sticks to assist in the activity may prevent them from the incidence of ulcers. ${ }^{14}$

PAD was significantly related to the incidence of ulcers by multivariate analysis. The result of OR was 7.749; this means that DM respondents who

\section{References}

1. American Diabetes Association. Diagnosis and classification of diabetes mellitus. Diabetes Care. 2009;32 Suppl 1:S62-S67.

2. Diabetes Atlas, Seventh Edition Committee. IDF Diabetes Atlas 7th Edition (2015). https://www.idf. org/our-activities/advocacy-awareness/resourcesand-tools/13:diabetes-atlas-seventh-edition.html. International Diabetes Federation; 2015. Accessed December 15, 2017.

3. Melville A, Richardson R, Mclntosh A, et al. Complications of diabetes: screening for retinopathy and management of foot ulcers. Qual Health Care. 2000;9:137-141. experienced PAD had 7.749 chance of occurrence of ulcers compared to respondents who did not experience PAD. The study of Leese et al. ${ }^{15}$ showed that respondents who experienced a lack of pulse were at 4.7 times of risk of ulcers compared with respondents who had strongly palpable pulse. People who experience PAD will have ulcers 10 times than people who do not experience PAD. ${ }^{16}$ PAD is a form of arteriosclerosis (stiffness and narrowing of blood vessels) due to deposits of fat or other substances that occur gradually. PAD severity indicates that there is pain at rest, difficult-to-heal wounds in the feet/fingers, and gangrene. The process of occurrence of PAD involves arterial thickening, arteriosclerosis, and tissue necrosis. ${ }^{16}$

Arterial thickening/hardening of the arteries or plaque makes the blood flow reduction, reducing the supply of oxygen and nutrients to the leg muscles. ${ }^{17-20}$ Tissue necrosis can occur due to reduced blood flow, hypoxia, so that infection and gangrene can occur and that may lead to amputation. ${ }^{21}$

\section{Conclusions}

There was no relationship between visual impairment and diabetic foot ulcers in Dr. Moewardi Hospital. However, there is a relationship between PAD and diabetic foot ulcers in Dr. Moewardi Hospital. Respondents with PAD are susceptible to foot ulcers, the risk can be 5.808 times higher than those who had not PAD. Suggestions of this study are to do foot screening and educate about the importance of foot care to prevent the occurrence of diabetic ulcers.

\section{Conflicts of interest}

All contributing authors declare no conflicts of interest.
4. Saikat Sen, Raja Chakraborty. EDITORIAL (Thematic issue: Treatment and Diagnosis of Diabetes Mellitus and Its Complication: Advanced Approaches). Mini-Reviews Med Chem. 2015;15:1132-1133.

5. Chen HL, Hsiao FY. Risk of hospitalization and healthcare cost associated with Diabetes Complication Severity Index in Taiwan's National Health Insurance Research Database. J Diabetes Complications. 2018;28:612-616.

6. Dalan R1, Jong M, Choo R, Chew DE, Leow MK. Predictors of cardiovascular complication in patients with diabetes mellitus: a 5-year follow-up study in a 
multiethnic population of Singapore: CREDENCE II study. Int J Cardiol. 2018;169:e67-e69.

7. Heitzman J. Foot Care for Patients With Diabetes. Top Geriatr Rehabil. 2010;26:250-263.

8. Frykberg RG, Zgonis T, Armstrong DG, et al. Diabetic foot disorders. A clinical practice guideline (2006 revision). J Foot Ankle Surg. 2006;45(5 Suppl):S1-S66.

9. Registered Nurses' Association of Ontario. Assessment and Management of Foot Ulcers for People with Diabetes Greetings from Doris Grinspun. Registered Nurses' Association of Ontario; 2005.

10. Sieggreen MY. Step up care for diabetic foot. Nurs Manage. 2006;37:25-31.

11. Silbernagl S, Lang F. Color Atlas of Pathophysiology, At a Glance. New York: Thieme; 2010.

12. Prompers L, Schaper N, Apelqvist J, et al. Prediction of outcome in individuals with diabetic foot ulcers: focus on the differences between individuals with and without peripheral arterial disease. The EURODIALE Study. Diabetologia. 2008;51: 747-755.

13. National Diabetes Education Program. Working Together to Manage Diabetes: A Guide for Pharmacy, Podiatry, Optometry, and Dentistry. National Institutes of Health and the Centers for Disease Control and Prevention; 2014. https://www.cdc. gov/diabetes/ndep/pdfs/ppod-guide.pdf. Accessed December 15, 2017.

14. Golledge J, Quigley F, Velu R, Walker PJ, Moxon JV. Association of impaired fasting glucose, diabetes and their management with the presentation and outcome of peripheral artery disease: a cohort study. Cardiovasc Diabetol. 2014;13:1-9.

15. Leese G, Schofield C, Mcmurray B, et al. Scottish foot ulcer risk score predicts foot ulcer healing in a regional specialist foot clinic. Diabetes Care. 2007;30: 2064-2069.

16. Edgar JGP, David GA, Lawrence AL. Risk factors for recurrent diabetic foot ulcers. Diabetes Care. 2007; 30: 2077-2079.

17. Nezarat N, Budoff MJ, Luo Y, et al. Presence, characteristics, and volumes of coronary plaque determined by computed tomography angiography in young type 2 diabetes mellitus. Am J Cardiol. 2018;119:1566-1571.

18. Modesti PA, Castellani S, Calabrese M, Malandrino D, Zhao D. Comparison of type 2 diabetes prevalence in Chinese migrants vs Caucasians and new perspectives for screening of cerebrovascular disease in Chinese: a proof of concept study. Diabetes Res Clin Pract. 2018;130:196-203.

19. Mrgan M, Funck KL, Gaur S, et al. High burden of coronary atherosclerosis in patients with a new diagnosis of type 2 diabetes. Diabetes Vasc Dis Res. 2017;14:468-476.

20. Wu Y, He J, Sun X, et al. Carotid atherosclerosis and its relationship to coronary heart disease and stroke risk in patients with type 2 diabetes mellitus. Medicine (Baltimore). 2017;96:e8151.

21. Hamburg NM, Balady GJ. Exercise rehabilitation in peripheral artery disease: functional impact and mechanisms of benefits. Circulation. 2011;123:87-97. 